\title{
Book Summary - How People Learn
}

$\mathrm{T}$ his book starts with a foreword by Roger Schank, John Evans Professor Emeritus at Northwestern University, USA and CEO of Socratic Arts. Following this is a preface, an introduction, nine chapters and a conclusion.

In the preface, the author, Nick Shackleton-Jones, sets out to explain the purpose of this book: the failures of education in helping people learn. Education is not about remembering things, but about having experiences, hearing stories of experiences and how they make people feel. In short, it is a book about cognition and creatures that think. He wrote the book with the aim of having a profound impact, not just on education and learning, but on artificial intelligence, ethics, language, and just about everything. The book is intended for two audiences: people who learn and people who work in learning, but will also be of interest to anyone interested in cognitive mechanisms and decision making.

\section{Introduction - Everything you know about learning is wrong}

This chapter starts by exploring an 1885 psychological experiment carried out by Herman Ebbinghaus, leading him to discover that meaningless information can be retained if it is repeated over and over again. This model became widely accepted for memory, learning and education, a method which became known as "rote learning". Where Ebbinghaus studied "memory," Frederic Bartlett studied "remembering," and his work is then explored in contrast to Ebbinghaus. Bartlett was a forerunner of cognitive and cultural psychology, taking an anthropological approach to psychology. In essence, people take on information by what things are important or meaningful to them, and that is the information that is retained in memory.

\section{Chapter 1 - Where's my robot or "what Al taught us about learning"}

This chapter begins with an explanation of why we don't have robots/Al doing our bidding, although it seemed likely in the post-Second World War years, and the reason is "we thought we understood ourselves, so we incorrectly assumed it would be easy to get computers to do what we do". The biggest obstacle to this is that computers don't understand and use words in the same way that humans do. The author's main point here is that "all of our words are feeling words", not just ones that convey emotions, but ones that describe an object, even objects as mundane and everyday as a chair. Until a computer is able to feel, it will never be able to think like a human does, and until this problem is solved, Al will never be on the same level as human intelligence. This misunderstanding of human learning, in which there needs to be a reaction/emotion to an experience/event instead of trying to memorize facts, has led to how education has been approached for decades. "The building blocks of learning are not facts or knowledge; instead they are reactions and stories and experiences".

\section{Chapter 2 - How we learn: The affective context model}

The author begins this chapter relaying experiences of school; do we remember what we learn? Or do we remember our experiences, people will largely remember events from 
school as opposed to things they were taught. This leads on to the unreliability of human memory, that memories of events can be distorted, patchy, unreliable, or in some cases, completely false. He explains the affective context model: we don't actually remember any of the experiences that happen to us. Instead we store our reactions to those events - these reactions are used to bring up a memory when required. This model has immeasurable consequences for education and learning: it does explain the shortcomings of methods used today, and can help inform the techniques that will be needed in the future for education and learning to be effective. The author summarizes: "our thoughts are made up of feelings, our memory is made up of feelings, our decisions are made up of feelings". The chapter ends with revised meanings of learning and memory - learning: a change in behaviour or capability as a result of memory; memory: the encoding of an effective response to an experience, which allows that experience to be reconstructed.

\section{Chapter 3 - Re-imagine your world}

The main theme of this chapter is that in humans, individual differences depend in a big way on the things that people care about. People try to share what they feel and experience when describing something to another person, and this should be the way that education and learning is delivered. For example, whether in business or higher education, people desire mentors and coaches, learners will listen more effectively to peers than instructors, when people move into a new culture such as a new job, what makes the most difference to their experience is someone who is there to help. If development and learning professionals really want to change behaviors, they must first understand the concerns that dictate how someone behaves in the first place.

\section{Chapter 4 - Learning design - push or pull?}

This chapter describes experiments undertaken by the author on how students have reacted to different types of learning materials: plain text, audio, video, audio and video together, and interactive exercises. In any learning design model, the creator of the content needs to be aware of whether they are responding to concerns a person already has (pull), or trying to create new concerns for the person (pull). Conversation is used as an example of push/pull learning, especially as conversation is actually one of the oldest learning methods there is. It is a way of telling stories.

The chapter goes into more detail to describe how "push" learning works, what it looks like, how it can be achieved and designing an experience. It goes further in describing different types of learning which are "push" methods:

\section{- Anxiety-based learning}

- Behavior modification.

- Observational learning.

- Anticipatory learning.

- Trial and error.

- Play.

- Feedback.

The last part of the chapter explores "pull" methods of learning, and delves deeply into resources, what resources actually are and how they can be utilized.

\section{Chapter 5 - Learning elimination: resources not courses}

This chapter follows on from the end of the previous one by looking at resources; "that resources work extraordinarily well in some circumstances but not at all in others is a 
reminder of how important it is to understand the concerns of your audience". The author gives an example of transforming the learning induction in a large global company, from mandatory learning (which was not actually being completed) to a completely different system that was not mandatory but had a much larger uptake and interaction. It also explains more about what a resource actually is, and people use them more than they realize, eg., taking a picture of a login or screenshot of a presentation slide is creating a resource, it is creating something you can refer back to instead of learning or memorizing it, and that resources are a "learning eliminator".

\section{Chapter 6 - Education: the great learning prevention scheme}

This chapter begins with the idea that the education system doesn't work or is ineffective, and there can't be an educational revolution until we understand properly about how learning actually works. For centuries, humans have been educated in the same manner. This chapter contains another case study, entitled Mud-pies: a story about applying educational methods to learning. The basic outcome is that education is such a poor model for learning, but is so accepted, as there is no alternative, that learning in the workplace just becomes a repeat of the type of learning models undertaken in schools, on the basis of rewards and punishment. In short, learning needs to move away from being a content dump, every innovation since pen and paper has just been another way to dump content on people, whether it be e-learning or VR. The two major problems with current education are: what people learn at school or university do not apply well to the world of work; the second problem is that education is mostly "push". The chapter ends with the author's purpose of education:

Education should support learning by providing a process that allows individuals both to discover a sense of purpose and to make it part of their working life.

\section{Chapter 7 - What to do about it: Techniques for human-centered learning design}

In this chapter the author describes some techniques for putting the affective context model of learning into practice. Firstly, stating that putting the model into practice quickly begins to look like human-centered learning design. The central idea here is to understand people's tasks and concerns, then design either resources or experiences as part of a learning solution. If this is applicable to learning programs, there will likely be a big shift in three things:

1. How successful these programs are.

2. The impact on behavior.

3. The experience of the programmer.

There are a number of steps involved in applying the affective context model to learning including:

- Define.

- Discover.

- Design.

- Develop.

- Deploy.

- Iterate.

The chapter also contains a case study, Big Shoes: a story about leadership. It describes how to make learning work for leaders, but a big message it what leaders expect to do, and 
what their employees expect them to do can be very different things; the human cost of poor leadership is sky-high.

The chapter ends by describing how you actually evaluate learning: actually measure performance; talk to your learners; give learners real work to do; award badges.

\section{Chapter 8 - Learning Culture}

This chapter begins discussing organizational cultures, and how learning cultures must be improved in tandem with that of the organization, but these attempts tend to follow the "enable, maintain, grow" model and can be ineffective. Different areas of organizations will benefit from different types of learning culture; the culture will be different for R\&D as it will be for sales. Challenging work is an effective way to enhance a learning culture, again it is not always applicable for every department in every organization. The author lists some shortcomings that occur when companies are trying to implement or improve learning culture/systems:

- These systems are often conducted annually or at most quarterly.

- Formal talent and learning methods are top down and don't consider the tasks done by the employee.

Implementing a learning culture is different to implementing an organizational culture, learning shouldn't come from the top down or it feels forced, and employees may resist that.

This chapter also contains a case study - Moo: Knowledge sharing. The author recounts his experience of building a video-sharing and blogging platform at the BBC called Moo, and explains the factors that made it a success.

\section{Chapter 9 - The future of learning (and how to make it happen)}

This chapter explains how much further there is to go to make learning and work integrated, and once they are - work will feel very different. The problem that needs to be solved is that organizational learning methods aren't designed to develop the employee or help them do their job, their design pushes content at them:

Put simply, unless we understand learning, we will not make progress in advancing education whether school/university or corporate.

The future of learning will be undertaken by:

- Shift from courses to resources.

- Shift from resources to guidance.

- Shift from guidance to automation.

The author next maps out how an organization that is focused on the employee experience in regards to learning might look:

- Experience and performance, not learning.

- Challenges not capabilities.

- Design for transitions.

- Audience (not SME) centric.

- Focus on performance (not content).

- Focus on employee experience rather than organizational structure.

- Iterative not static development. 
- Product not programme.

- Content strategy not curriculum.

- Open to all.

- Digital first.

- Experiential, not instructional.

- Resources become guidance.

Organizations need to provide experiences and resources from which employees can learn, but essentially learning is the role of the learner.

\section{Conclusion}

The book concludes with a final case study - Bananas: a story about memorability. The author, at a conference, put bananas under some chairs, those with bananas were asked up on stage and had to peel and eat bananas in synchronization, to music. The point being made was the people would barely remember anything they were told after two days at a conference, but everyone would remember the bananas.

For instructions on how to order reprints of this article, please visit our website: www.emeraldgrouppublishing.com/licensing/reprints.htm

Or contact us for further details: permissions@emeraldinsight.com 